\title{
PENGARUH KONSENTRASI BORON TERHADAP PERTUMBUHAN DAN PRODUKSI DUA VARIETAS MENTIMUN (Cucumis Sativus L) YANG DITANAM SECARA HIDROPONIK
}

\author{
Annisa Rahmasuri, Yohannes Cahya Ginting \& Azlina Heryati Bakrie \\ Jurusan Agroteknologi, Fakultas Pertanian Universitas Lampung \\ Jl. Prof. Dr. Soemantri Brodjonegoro No. 1 Bandar Lampung 35145 \\ E-mail : Annisa_maru@yahoo.com
}

\begin{abstract}
ABSTRAK
Mentimun merupakan salah satu jenis sayuran buah yang sangat potensial dikembangkan untuk memenuhi kebutuhan masyarakat yang semakin meningkat. Salah satu upaya untuk meningkatkan persediaan mentimun yaitu dengan menerapkan sistem hidroponik. Konsentrasi boron dalam budidaya mentimun dengan sistem hidroponik di dataran rendah belum diketahui, padahal boron merupakan salah satu unsur hara mikro yang sangat penting untuk pertumbhan mentimun. Penelitian ini bertujuan untuk mengetahui pengaruh pemberian boron (B) terhadap dua varietas mentimun yang ditanam secara hidroponik. Penelitian ini dilaksanakan di Rumah Kaca Fakultas Pertanian Universitas Lampung pada bulan September 2012 - Januari 2013. Penelitian ini menggunakan rancangan acak kelompok Lengkap (RAKL) pola faktorial yang terdiri dari 2 faktor. Faktor pertama adalah konsentrasi boron (B) yaitu: $b_{1}=0,10 \mathrm{ppm}, \mathrm{b}_{2}=0,25 \mathrm{ppm}, \mathrm{b}_{3}=0,40 \mathrm{ppm}, \mathrm{b}_{4}=0,55 \mathrm{ppm}$, dan $\mathrm{b}_{5}=0,70 \mathrm{ppm}$. Faktor kedua adalah varietas tanaman mentimun $(\mathrm{V})$, yaitu $\mathrm{v}_{1}=$ varietas Roman dan $\mathrm{v}_{2}=$ varietas Soarer. Homogenitas ragam diuji dengan uji Bartlett dan kemenambahan data diuji dengan uji Tuckey. Jika asumsi terpenuhi, data dianalisis ragam dan dilanjutkan dengan uji ortogonal kontras pada taraf $5 \%$. Hasil penelitian menunjukkan: (1) konsentrasi boron (B) dari 0,1-0,7 ppm tidak berpengaruh terhadap pertumbuhan dan produksi kedua varietas mentimun (Roman dan Soarer), sehingga belum diperoleh pertumbuhan dan produksi terbaik. (2) Varietas Soarer menghasilkan pertumbuhan dan produksi yang lebih baik daripada varietas Roman. Rata-rata buah yang dihasilkan varietas Soarer yaitu 6 buah sedangkan varietas Roman yaitu 3 buah. (3) Tidak terdapat interaksi antara varietas mentimun dan konsentrasi boron terhadap semua variabel, baik variabel pertumbuhan vegetatif maupun komponen generatif.
\end{abstract}

Kata kunci : Boron, hidroponik, mentimun, varietas Roman, varietas Soarer.

\section{PENDAHULUAN}

Tanaman mentimun (Cucumis sativa $\mathrm{L}$ ) termasuk dalam tanaman merambat yang merupakan salah satu jenis tanaman sayuran dari keluarga Cucurbitaceae. Pembudidayaan mentimun sudah meluas ke seluruh dunia, baik di daerah beriklim panas (tropis) maupun sedang (sub-tropis). Di Indonesia tanaman mentimun banyak di tanam di dataran rendah (Wijoyo, 2012).

Buah mentimun memiliki bermacam-macam manfaat dalam kehidupan sehari-hari, antara lain sebagai bahan makanan, bahan untuk obat-obatan dan bahan kosmetik. Permintaan terhadap komoditas ini sangat dibutuhkan dalam jumlah besar dan berkesinambungan. Kebutuhan buah mentimun ini akan meningkat terus sejalan dengan kenaikan jumlah penduduk, kenaikan taraf hidup masyarakat, tingkat pendidikan masyarakat dan semakin tingginya kesadaran masyarakat terhadap pentingnya nilai gizi (Wijoyo, 2012).

Produksi mentimun di Indonesia masih rendah padahal potensinya cukup tinggi. Kebanyakan para petani mentimun di Indonesia masih menganggap bertanam mentimun adalah usaha sampingan, sehingga penanganannya pun masih belum optimal. Produksi mentimun di Indonesia masih sangat rendah yaitu 3,5 ton/ha sampai 4,8 ton/ha, padahal produksi mentimun bisa mencapai lebih dari 20 ton/ha (Mardalena, 2007).

Rendahnya produksi mentimun dapat dipengaruhi oleh jenis varietas yang digunakan dan suplai unsur hara yang diberikan. Kekurangan dan kelebihan unsur hara dapat mengakibatkan pertumbuhan tanaman secara keseluruhan akan terganggu atau tidak sempurna, sehingga produksinya rendah. Khusus mengenai unsur hara mikro belum menjadi perhatian kita, padahal unsur hara mikro juga sebagai salah satu faktor penentu 
produksi. Salah satu unsur mikro yang sering menjadi faktor pembatas produksi mentimun adalah boron.

Salamala (1990) melaporkan bahwa defisiensi unsur mikro terutama boron dapat menyebabkan abnormalitas kakao di lapang. Selanjutnya dinyatakan bahwa gejala defisiensi boron pada kakao menyebabkan pertumbuhan vegetatif yang sangat tinggi tetapi pemberian boron dapat meningkatkan pertumbuhan bunga dan pembentukan buah kakao.

Penelitian ini bertujuan untuk mengetahui konsentrasi boron terbaik bagi pertumbuhan dan produksi dua varietas mentimun. Untuk mengetahui apakah varietas lokal lebih baik daripada varietas introduksi. Untuk mengetahui pengaruh interaksi antara varietas dan konsentrasi boron (B) yang diberikan pada pertumbuhan dan produksi tanaman mentimun.

\section{BAHAN DAN METODE}

Penelitian ini dilaksanakan di Rumah Kaca Fakultas Pertanian Universitas Lampung dari bulan September 2012 sampai bulan Januari 2013. Bahan bahan yang digunakan dalam penelitian ini adalah arang sekam, benih mentimun hibrida varietas Roman dan varietas Soarer, asam boraks, NPK mutiara, urea, kalsium klorida, magnesium sulfat, besi sulfat, mangan sulfat, asam boraks, tembaga sulfat, seng sulfat, natrium molibad, Dithane dan Antraxtan.

Metode penelitian yang digunakan adalah rancangan acak kelompok lengkap (RAKL). Perlakuan disusun secara faktorial $2 \times 5$ dengan 3 kali ulangan. Faktor pertama adalah varietas $(\mathrm{V})$, yaitu $\mathrm{v}_{1}=$ varietas Roman dan $\mathrm{v}_{2}=$ varietas Soarer. Faktor kedua adalah konsentrasi Boron (B), yaitu $b_{1}=0,1 \mathrm{ppm}, \mathrm{b}_{2}=0,25 \mathrm{ppm}$, $\mathrm{b}_{3}=0,4 \mathrm{ppm}, \mathrm{b}_{4}=0,55 \mathrm{ppm}$ dan $\mathrm{b}_{5}=0,7 \mathrm{ppm}$. Homogenitas ragam diuji dengan uji Bartlett dan kemenambahan data diuji dengan uji Tukey. Jika asumsi terpenuhi, data dianalisis ragam dan dilanjutkan dengan uji ortogonal kontras pada taraf $5 \%$.

Benih mentimun yang telah disemai dipindahkan ke dalam polybag yang berisi media arang sekam. Penyiraman dilakukan tiga kali sehari dengan larutan hara yang telah terdapat unsur boron, dengan konsentrasi boron (B) sesuai perlakuan yaitu 0,$1 ; 0,25 ; 0,4 ; 0,55$; dan 0,7 ppm. Unsur boron dengan masing-masing konsentrasi tersebut dilarutkan dan dicampurkan dengan unsur hara makro dan mikro lainnya, kemudian diberikan pada tanaman mentimun setiap penyiraman. Pada saat mulai tanam, jumlah larutan yang diberikan dari $50 \mathrm{ml}$ per tanaman dan meningkat terus sampai $300 \mathrm{ml}$ per tanaman dari pertumbuhan tanaman hingga tanaman berbuah. Dosis boron (B) yang dibutuhkan selama penelitian yaitu 708 gtan $^{-1}$ pada konsentrasi $0,1 \mathrm{ppm}$, $1771 \mathrm{gtan}^{-1}$ pada konsentrasi $0,25 \mathrm{ppm}, 2834 \mathrm{gtan}^{-1}$ pada konsentrasi 0,40 ppm, 3897 gtan $^{-1}$ pada konsentrasi 0,55 ppm, dan 4960 gtan $^{-1}$ pada konsentrasi $0,70 \mathrm{ppm}$. Variabel yang diamati adalah panjang tanaman, jumlah daun, jumlah bunga, jumlah buah, panjang buah, diameter buah, tebal daging buah, bobot buah, bobot berangkasan dan produksi.

\section{HASIL DAN PEMBAHASAN}

Hasil penelitian menunjukkan bahwa jumlah bunga betina dan jumlah buah varietas Soarer lebih banyak daripada varietas Roman, tetapi jumlah bunga jantan varietas Roman lebih banyak daripada varietas Soarer. Banyaknya jumlah bunga betina dan jumlah buah pada varietas Soarer merupakan keunggulan dari karakteristik varietas itu sendiri (Tabel 1 dan 2)

Dalam penelitian ini, buah yang dihasilkan varietas Roman rata-rata tiga buah per tanaman dengan bobot rata-rata $234 \mathrm{~g} /$ buah. Jika dibandingkan dengan potensinya, yaitu varietas Roman dapat menghasilkan 6-8 buah per tanaman dengan bobot 390-400 g/buah. Hal ini menunjukkan rata-rata hasil mentimun varietas Roman yang dihasilkan termasuk dalam kategori rendah karena berdasarkan hasil penelitian menunjukkan hasil produksi buah mentimun serta bobot buah mentimun masih di bawah potensi.

Varietas Soarer mampu menghasilkan rata-rata bobot buah 216,46 g/buah dengan panjang buah 26,8 $\mathrm{cm}$, diameter buah $3,5 \mathrm{~cm}$, dan menghasilkan enam buah per tanaman. Hasil ini lebih tinggi dari potensinya yaitu rata-rata bobot buah 90-100 g/buah dengan diameter 2,5-3 cm, panjang buah $26,8 \mathrm{~cm}$, dan jumlah buah per tanaman 6-8. Hal ini diduga karena dengan sistem hidroponik, mentimun varietas introduksi lebih mampu memanfaatkan ketersediaan hara yang cukup untuk tumbuh lebih produktif. Untuk variabel jumlah buah, varietas Soarer menghasilkan rata-rata buah sebanyak 6 buah per tanaman, jumlah ini lebih tinggi daripada varietas Roman yang menghasilkan rata-rata jumlah 3 hanya tiga buah per tanaman.

Banyaknya jumlah bunga betina dan jumlah buah pada varietas Soarer merupakan keunggulan dari karakteristik varietas itu sendiri. Banyaknya jumlah buah yang dihasilkan berkaitan dengan banyaknya jumlah bunga betina yang dihasilkan, karena bunga betinalah yang berpotensi membentuk buah. Menurut Sutapradja (2008) pada fase generatif hampir seluruh hasil fotosintesis akan digunakan oleh bunga dan buah yang sedang berkembang. Menurut Sasmito (2005) dalam Rahmawati (2009) bahwa hasil panen tergantung dari 
Tabel 1. Pengaruh varietas dan konsentrasi boron pada variabel vegetatif tanaman mentimun.

\begin{tabular}{|c|c|c|c|}
\hline \multirow{3}{*}{ Perbandingan } & Panjang Tanama n & Jumlah Daun & Bobot Kering Berangkasan \\
\hline & \multicolumn{3}{|c|}{ F Hit ung } \\
\hline & $\mathrm{cm}(\%)$ & helai (\%) & $\operatorname{gram}(\%)$ \\
\hline $\begin{array}{l}\text { Varietas } \\
\text { C1: Roman vs Soarer }\end{array}$ & $\begin{array}{l}0,19^{\mathrm{tn}} \\
(6,03 \%)\end{array}$ & $\begin{array}{c}0,33^{\mathrm{tn}} \\
(-0,79 \%)\end{array}$ & $\begin{array}{c}0,33^{\mathrm{tn}} \\
(9,25 \%)\end{array}$ \\
\hline $\begin{array}{l}\text { Dosis pupuk boron (B) } \\
\text { C2 : B Linear } \\
\text { C } 3: \text { B Kuadratik }\end{array}$ & $\begin{array}{l}0,06^{\mathrm{tn}} \\
0,34^{\mathrm{tn}}\end{array}$ & $\begin{array}{l}0,82^{\mathrm{tn}} \\
0,09^{\mathrm{tn}}\end{array}$ & $\begin{array}{l}0,11^{\mathrm{tn}} \\
0,08^{\mathrm{tn}}\end{array}$ \\
\hline $\begin{array}{l}\text { Interaksi } \\
\mathrm{C} 4: \mathrm{C} 1 \times \mathrm{C} 2 \\
\mathrm{C} 5: \mathrm{C} 1 \times \mathrm{C} 3\end{array}$ & $\begin{array}{l}0,06^{\mathrm{tn}} \\
0,34^{\mathrm{tn}}\end{array}$ & $\begin{array}{l}0,04^{\mathrm{tn}} \\
0,48^{\mathrm{tn}}\end{array}$ & $\begin{array}{l}0,19^{\mathrm{tn}} \\
2,33^{\mathrm{tn}}\end{array}$ \\
\hline
\end{tabular}

Keterangan: $\mathrm{F}$ tabel $0,05=4,41, \mathrm{tn}=$ tidak berbeda nyata pada taraf $5 \%$, angka dalam kurung merupakan selisih antara varietas Roman dan Soarer (\%).

Tabel 2. Pengaruh varietas dan konsentrasi boron pada variabel generatif tanaman mentimun.

\begin{tabular}{|c|c|c|c|c|}
\hline \multirow[t]{3}{*}{ Perbandingan } & Bung a Jantan & Bunga Betina & Jumlah Buah & Panjang Buah \\
\hline & \multicolumn{4}{|c|}{ F Hitung } \\
\hline & (kuntum) & (kuntum) & (buah) & $(\mathrm{cm})$ \\
\hline $\begin{array}{l}\text { Varietas } \\
\text { C1 : Roman vs Soarer }\end{array}$ & $\begin{array}{c}6,53^{*} \\
(317,48 \%)\end{array}$ & $\begin{array}{c}6,39^{*} \\
(-59,28 \%)\end{array}$ & $\begin{array}{c}5,53^{*} \\
(-53,92 \%)\end{array}$ & $\begin{array}{c}0,26^{\mathrm{tn}} \\
(-19,85 \%)\end{array}$ \\
\hline $\begin{array}{l}\text { Dosis pupuk boron (B) } \\
\text { C2 : B Linear } \\
\text { C3 : B Kuadratik }\end{array}$ & $\begin{array}{l}0,81^{\text {tn }} \\
0,14^{\text {tn }}\end{array}$ & $\begin{array}{l}0,42^{\mathrm{tn}} \\
0,23^{\mathrm{tn}}\end{array}$ & $\begin{array}{l}0,08^{\mathrm{tn}} \\
0,18^{\mathrm{tn}}\end{array}$ & $\begin{array}{l}0,15^{\text {tn }} \\
0,16^{\text {tn }}\end{array}$ \\
\hline $\begin{array}{l}\text { Interaksi } \\
\mathrm{C} 4: \mathrm{C} 1 \text { x C2 } \\
\mathrm{C} 5: \mathrm{C} 1 \text { x C3 }\end{array}$ & $\begin{array}{l}0,06^{\mathrm{tn}} \\
0,61^{\mathrm{tn}}\end{array}$ & $\begin{array}{l}0,26^{\mathrm{tn}} \\
1,05^{\mathrm{tn}}\end{array}$ & $\begin{array}{l}0,10^{\text {tn }} \\
0,15^{\text {tn }}\end{array}$ & $\begin{array}{l}0,12^{\text {tn }} \\
0,67^{\text {tn }}\end{array}$ \\
\hline \multirow[t]{3}{*}{ Perbandingan } & Diameter Buah & Tebal Daging Buah & Bobot Buah & Produksi \\
\hline & \multicolumn{4}{|c|}{ F Hitung } \\
\hline & $(\mathrm{cm})$ & $(\mathrm{cm})$ & (gram) & (gram) \\
\hline $\begin{array}{l}\text { Varietas } \\
\text { C1 : Roman vs Soarer }\end{array}$ & $\begin{array}{c}0,19^{\mathrm{tn}} \\
(10,69 \%)\end{array}$ & $\begin{array}{c}0,047^{\mathrm{tn}} \\
(3,317 \%)\end{array}$ & $\begin{array}{l}0,0006^{\mathrm{tn}} \\
(8,19 \%)\end{array}$ & $\begin{array}{c}1,51^{\mathrm{tn}} \\
(-16,88 \%)\end{array}$ \\
\hline $\begin{array}{l}\text { Dosis pupuk boron (B) } \\
\text { C2 : B Linear } \\
\text { C3 : B Kuadratik }\end{array}$ & $\begin{array}{l}0,2^{\text {tn }} \\
0,12^{\text {tn }}\end{array}$ & $\begin{array}{l}0,008^{\text {tn }} \\
0,075^{\text {tn }}\end{array}$ & $\begin{array}{l}0,18^{\mathrm{tn}} \\
0,21^{\mathrm{tn}}\end{array}$ & $\begin{array}{l}0,1^{\mathrm{tn}} \\
0,25^{\mathrm{tn}}\end{array}$ \\
\hline $\begin{array}{l}\text { Interaksi } \\
\text { C4 : C1 x C2 } \\
\text { C5 : C } 1 \times \text { C } 3\end{array}$ & $\begin{array}{l}0,15^{\mathrm{tn}} \\
0,51^{\mathrm{tn}}\end{array}$ & $\begin{array}{l}0,377^{\text {tn }} \\
0,903^{\text {tn }}\end{array}$ & $0,07^{\mathrm{tn}}$ & $\begin{array}{l}0,003^{\text {tn }} \\
0,297^{\text {tn }}\end{array}$ \\
\hline
\end{tabular}

Keterangan: $\mathrm{F}$ tabel $0,05=4,41, *=$ berbeda nyata pada taraf $5 \%, \mathrm{tn}=$ tidak berbeda nyata pada taraf $5 \%$, angka dalam kurung merupakan selisih antara varietas Roman dan Soarer (\%). 
banyaknya bunga betina yang dihasilkan. Salah satu faktor yang menyebabkan jumlah buah varietas Soarer lebih banyak adalah jumlah bunga betina pada varietas Soarer lebih banyak daripada varietas Roman. Secara genetis, bunga betina pada mentimun varietas Soarer lebih cepat terbentuk dan lebih banyak.

Penelitian ini dilakukan pada musim kemarau oleh karena itu suhu dalam rumah kaca relatif tinggi, ini merupakan salah satu faktor penyebab rendahnya pembentukan bunga betina. Menurut Juwita (2007) pada musim kemarau, tanaman mengalami penyinaran sinar matahari yang cukup panjang dengan intensitas yang tinggi maka suhu udara menjadi panas. Hal ini menyebabkan tanaman mentimun cenderung memperlihatkan lebih banyak bunga jantan dari pada bunga betina. Hasil penelitian ini menunjukkan bahwa varietas Soarer justru lebih toleran terhadap suhu panas sehingga berkaitan dengan pembentukan bunga betina. Dengan demikian banyaknya jumlah buah yang terdapat pada tanaman mentimun juga tergantung pada jumlah bunga betina yang dihasilkan oleh tanaman mentimun.

Secara umum kemampuan adaptasi varietas hibrida introduksi lebih rendah daripada hibrida lokal (Idris, 2004). Berbeda dengan mentimun hibrida introduksi, jenis mentimun hibrida lokal umumnya cocok ditanam di dataran rendah (Wijoyo, 2012). Namun pada penelitian ini produksi mentimun varietas Soarer (hibrida introduksi) lebih baik daripada produksi mentimun varietas Roman (hibrida lokal). Hal ini ditunjukkan dengan kemampuan varietas Soarer menghasilkan jumlah buah yang lebih banyak. Hal ini dapat terjadi karena varietas Soarer memiliki kemampuan memanfaatkan ketersediaan hara yang diberikan melalui sistem hidroponik lebih tinggi daripada varietas Roman.

Menurut penelitian yang dilakukan oleh Resh (2004), kebutuhan unsur boron untuk tanaman hidroponik mentimun yaitu $0,5 \mathrm{mg} / \mathrm{L}$ (ppm). Berdasarkan penelitian yang telah dilakukan menunjukkan bahwa pemberian konsentrasi boron (B) 0,1 ppm sampai 0,7 ppm pada tanaman mentimun tidak berpengaruh terhadap semua variabel pengamatan, baik variabel pertumbuhan vegetatif maupun generatif. Hal ini menunjukkan bahwa konsentrasi boron $0,10 \mathrm{ppm}$ sampai $0,70 \mathrm{ppm}$ untuk mentimun masih dalam batas toleran, oleh karena itu pengujian pengaruh konsentrasi boron dapat dilakukan pada konsentrasi di atas $0,70 \mathrm{ppm}$.

Boron berperan penting sebagai aktifator maupun inaktifator hormon auksin dalam pembelahan dan pembesaran sel, sehingga apabila kekurangan unsur ini pertumbuhan vegetatif tanaman akan terhambat (Wijaya, 2009). Selain itu, boron juga berperan dalam pembentukan buah, pembentukan titik tumbuh dan penyerbukan (Masbied, 2011). Penelitian ini menggunakan sistem hidroponik dengan perlakuan unsur hara boron (B) yang dapat diterapkan oleh masyarakat. Akan tetapi, konsentrasi boron yang diberikan kemungkinan ditingkatkan antara 0,5 sampai 2,5 ppm. Selain itu penggunaan benih mentimun varietas Soarer dapat diterapkan karena buah yang dihasilkan sesuai potensinya mancapai 6 buah pertanaman dan cocok ditanam di daerah dataran rendah.

\section{KESIMPULAN}

Berdasarkan hasil penelitian yang telah dilaksanakan dapat disimpulkan bahwa kisaran konsentrasi boron (B) dari 0,1 sampai 0,7 ppm tidak berpengaruh terhadap pertumbuhan dan produksi kedua varietas mentimun (Roman dan Soarer), sehingga belum diperoleh pertumbuhan dan produksi terbaik. Penggunaan varietas Soarer dengan menggunakan sistem hidroponik menghasilkan pertumbuhan dan produksi yang lebih tinggi daripada varietas Roman. Rata-rata buah yang dihasilkan varietas Soarer 6 buah, sedangkan varietas Roman 3 buah. Tidak ada ketergantungan antara interaksi boron dan jenis varietas pada semua variabel pengamatan.

\section{SANWACANA}

Ucapan terima kasih disampaikan kepada Ibu Ir. Rugayah, M. S. yang telah membantu memberikan ide, bimbingan, motivasi, arahan, dan saran selama penelitian sampai penyelesaian skripsi ini dengan penuh kesabaran.

\section{DAFTAR PUSTAKA}

Idris. 2004. Respon tanaman mentimun (Cucumis sativus $\mathrm{L}$ ) akibat pemangkasan dan pemberian pupuk ZA. Jurnal Penelitian Bidang Ilmu Pertanian. 2 (1): 17-24.

Juwita, M. dan T. Sudartini. 2007. Pertumbuhan dan hasil mentimun (Cucumis sativus L.) varietas venus pada frekuensi dan konsentrasi mikroba efektif yang berbeda. Universitas Siliwangi Tasikmalaya. Jurnal Penelitian Bidang Ilmu Pertanian. 2 (1): 17-24.

Masbied. 2011. Identifikasi Gejala Defisiensi dan Kelebihan Unsur Hara Mikro pada Tanaman. http://www.masbied.com/2011/05/20/identifikasigejala-defisiensi-dan-kelebihan-unsur-hara-mikro- 
pada-tanaman/. Diakses pada tanggal : 1 Mei 2012.

Rahmawati, N. 2009. Pengaruh Varietas dan Konsentrasi Ethepon pada Pertumbuhan dan Hasil Panen Tanaman Mentimun (Cucumis sativus L) dalam Budidaya Hidroponik. (Skripsi). Institut Pertanian Bogor. Bogor.

Resh. 2004. Hydroponic Food Production Sixth Edition. New Jersey. Newconcept. 567 page

Salamala, M. 1990. Pengaruh Zat Pengatur Tumbuh Auksin dan Unsur Mikro terhadap Kakao (Theobroma cacao L). (Tesis). Institut Pertanian Bogor. Bogor.
Sasmito, M. A. 2005. Pengaruh Perlakuan Ethrel dan NAA terhadap Pembentukan Bunga dan Nisbah Kelamin Tanaman Mentimun (Cucumis sativus). (Skripsi). Institut Pertanian Bogor

Sutapradja, H. 2008. Pengaruh pemangkasan pucuk terhadap hasil dan kualitas benih lima kultivar mentimun. Jurnal Hortikultura. 18(1): 16-20.

Wijaya, Y. 2009. Unsur Hara Esensial yang Dibutuhkan Tanaman. http://yudhiwijaya. wordpress.com. Diakses pada tanggal : $16 \mathrm{Mei}$ 2013.

Wijoyo, P. M. 2012. Budidaya Mentimun yang Lebih Menguntungkan. PT Pustaka Agro Indonesia. Jakarta. 69 hal 